\title{
THE ROLE OF GALECTIN-9 IN PATIENTS WITH CHRONIC VIRAL HEPATITIS C AND ITS CONNECTION WITH THE TYPE OF THERAPY, THE DEGREE OF FIBROSIS, CLINICAL, LABORATORY, AUTOIMMUNE AND INTEGRATIVE INDICATORS
}

DOI: 10.36740/WLek202105125

\author{
Mykola D. Chemych, Anastasiia G. Lishnevska \\ SUMY STATE UNIVERSITY, SUMY, UKRAINE
}

\begin{abstract}
The aim: To establish the dependence of the concentration of galectin-9 (CGal-9) in the serum of patients with chronic viral hepatitis C(CVHC) on the type of antiviral therapy (AVT), clinical-laboratory, autoimmune and integrative parameters, non-invasive methods of assessing the degree of fibrosis.

Materials and methods: CGal-9 in serum were determined in 68 patients with CVHC and 20 healthy individuals, and clinical-laboratory and integrative parameters, noninvasive methods for assessing the degree of fibrosis were studied.

Results: There were three groups: baseline (I), pegylated interferon (PEG-IFN) with ribavirin (II), velpatasvir with sofosbuvir (III). In pations from group I, compared with healthy people, CGal-9 was 1.7 times higher ( $p<0.05)$; in patients from group II it was 4.2 times higher $(\mathrm{p}<0.05)$; in patients from group III it did not differ from healthy individuals. All patients had a directly proportional correlation between (Gal-9 and the frequency of splenomegaly detection; in patients who did not receive AVT, directly proportional - with De Ritis ratio, non-invasive methods of liver fibrosis, inversely proportional - with platelet count $(p<0,05)$. There was a higher probability of positive indicators of antinuclear antibodies (ANA) at 12 weeks of treatment with PEG-IFN and ribavirin, with higher (Gal-9 at 4 weeks of AVT $(p<0,05)$.

Conclusions: Correlations between CGal-9 and the frequency of splenomegaly detection, platelet count, De Ritis ratio, degree of lever fibrosis in correlation with METAVIR, APRI, FIB-4, ANA, NI were determined. The possibility of predicting the occurrence of splenomegaly, liver cirrhosis and positive ANA in patients with CVHC has been proven.
\end{abstract}

KEY WORDS: chronic viral hepatitis C, galectin-9, antibodies, liver fibrosis

Wiad Lek. 2021;74(5):1180-1188

\section{INTRODUCTION}

Recently, the role of glycan-lectin interactions in the formation of cooperation between the human body and the microorganism is becoming increasingly valuable. The focus is on the lectin families, galectins, and the diverse role that these glycan-binding proteins play in a number of viral infections, including viral hepatitis $\mathrm{C}$.

The main role of galectin-9 in the persistence of hepatitis $\mathrm{C}$ virus (HCV) is that it infects hepatocytes and induces their death. Thus, the cell expresses phosphatidylserine molecules on the outer surface of the membrane. When the cell is apoptotic, it presents phosphatidylserine on the outer membrane of the cell, which is used as a ligand by phagocytic cells (monocytes/ macrophages) through such receptors as integrin $[1,2]$. These phosphatidylserine molecules are then recognized by expressed integrins represented by Kupffer cells, which are CD14 + macrophages in the liver. These cells then release galectin-9, which activates natural killers cells (NK cells) through a receptor that is still unknown. NK cells lyse, on the one hand, CD4 + T-leukocytes, and CD8 + remain there, which contributes to the preservation of the virus. On the other hand, NK cells lyse hepatocytes, thereby enhancing apoptosis, Kupffer cell activation, and galectin-9 production. [3].

It was found that CGal-9 was increased in the blood and liver of patients with CVHC. The accumulation of this lectin localized in Kupffer cells in high concentrations is characteristic of patients infected with HCV. Galectin-9 induces apoptosis of antigen-specific $\mathrm{T}$ cells by increasing the number of inhibitory T-regulatory cells. This proves that CVHC can stimulate chronic activity of galectin-9 (in combination with Tim-3), which leads to immune suppression and chronicity of the process [4]. Understanding the connection between galectin-9 concentrations and clinical and laboratory data may improve our knowledge of the effects of the described mechanisms on the course of CVHC.

\section{THE AIM}

To establish the dependence of the concentration of galectin-9 in the serum of patients with CVHC on the type of AVT, clinical, hematological, biochemical, autoimmune and integrative parameters, non-invasive methods for assessing the degree of liver fibrosis. 


\section{MATERIALS AND METHODS}

In order to carry out the study, CGal-9 in serum was detected in 88 patients (68 patients with CVHC and 20 healthy individuals). The infected patients were treated at the municipal non-commercial enterprise of Sumy Regional Council «Medical Clinical Center of Infectious Diseases and Dermatology named after Z.Y. Krasovytskyi", and their medical records of inpatients and outpatients were analyzed. Healthy individuals underwent a routine medical examination at the University Clinic of Sumy State University.

All patients were divided into 3 groups, depending on the treatment received: baseline therapy (pathogenetic and symptomatic) - 20 people (group I), PEG-IFN in combination with ribavirin - 24 people (group II), velpatasvir with sofosbuvir - 24 persons (III group). The concentration of galectin- 9 for group I was determined at hospitalization, for groups II and III - after 4 weeks of AVT.

Patients underwent clinical blood tests (Elite 3, CobasMicros), biochemical blood tests (ChemWell, COBASEMira) prior to and at 4 and 12 weeks of AVT. Polymerase chain reaction (PCR) in order to verify the diagnosis, establish the genotype of the virus and determine fibrosis using FIBROTEST (METAVIR) was performed in a commercial laboratory "Synevo". General integrative indices (integral severity index - ISI, entropy of leukocyte formula), indices of nonspecific reactivity (resistance coefficient - RC, immunoreactivity index - IR, neutrophil-lymphocyte ratio - NLR, lymphocyte-monocyte ratio - LMR, lymphocyte index - Ilymph, eosinophils-lymphocytes ratio - ELR, index of allergization - IA, nuclear index - NI); indexes of activity of inflammation (total index of inflammation - TII, Krebs index - KI, lymphocytic-granulocytic index - ILG, index of leukocyte and ESR ratio - ILESR), indexes of intoxication (leucocyte intoxication index - LII, aggression index - Iagr, hematological index of intoxication - HII, leukocyte shift index - LSI, index of intoxication severity - IIS, neutrophil reactive response - NRR) were calculated $[5,6,7]$.

APRI was calculated for all infected (AST to Platelet Ratio Index $=($ AST $\times 100 /($ upper limit of AST $) \times$ platelets $\left.\left(10^{9} / 1\right)\right)$ and FIB-4 (Fibrosis-4 Index for Liver Fibrosis = (age) $\times \mathrm{AST} /\left(\right.$ platelets $\left(10^{9} / \mathrm{l}\right) \times$ sqrt $($ ALT $\left.)\right)$.

The level of galectin-9 was determined by enzymelinked immunosorbent assay type «sandwich» according to the protocol to the set "Human Calectin-9 ELISA Kit (ab213786)». Patients' serum was diluted twice. After preparation of all reagents, samples and standards according to the instructions, $100 \mu$ lof standard was added, incubated at $37^{\circ} \mathrm{C}$ for $90 \mathrm{~min}$. Then $100 \mu \mathrm{l}$ of biotinylated antibody was added to all wells, incubated at $37^{\circ} \mathrm{C}$ for 60 min. After that, each well was washed three times with 300 $\mu \mathrm{l}$ of 0.01 TBS. $100 \mu \mathrm{l}$ of $\mathrm{ABC}$ working solution was added and incubated at $37^{\circ} \mathrm{C}$ for 30 minutes. Later on, each well was washed five times with $300 \mu \mathrm{l}$ of $0.01 \mathrm{M}$ TBS, $90 \mu \mathrm{l}$ of prepared TMB was added, and incubated at $37^{\circ} \mathrm{C}$ in the dark for $25 \mathrm{~min}$. Then stop solution TMB $100 \mu \mathrm{l}$ was added and read by ELISA (Thermo Scientific Multiskan FC) at $450 \mathrm{~nm}$ for 30 minutes.
Collection, adjustment, systematization of source information and visualization of the results were performed in spreadsheets of Microsoft Office Excel 2016. Statistical analysis was carried out using IBM SPSS Statistics v.23 (IBM Corporation).

Quantitative indicators were evaluated for compliance with the normal distribution, using the Shapiro-Wilk test. The study materials were subjected to statistical processing using non-parametric analysis methods. Quantitative indicators were described using the values of the median $(\mathrm{Me})$, lower and upper quartiles (Q1-Q3). The Mann-Whitney U-test was used to compare independent populations in the absence of signs of normal data distribution. Pearson's $\chi 2$-test was used to compare nominal variables. When establishing correlations between two quantitative traits, the Spearman correlation coefficient was calculated. To establish the relationship between qualitative and quantitative values, a ROC analysis was performed to determine AUROC. The significance of the criteria was considered reliable at $\mathrm{p}<0.05$.

The research was performed in compliance with international and national legislation on ethics in accordance with the requirements of the law of Ukraine on September 23, 2009 № 690 "On approval of the procedure for clinical trials of drugs and examination of clinical trial materials and standard regulations of the ethics commission." The design of the study was approved by the commission on bioethics in conducting experimental studies of the Medical Institute of Sumy State University. All patients and healthy individuals in the control group received informed consent to participate in the study in accordance with the Helsinki Declaration of the World Medical Association "Ethical principles of medical research with human participation as the object of study."

\section{RESULTS}

Among all patients, men predominated (61.76\%) compared with women (38.24\%). The distribution by gender was even in the groups (I $-65.00 \%$ of men and $35.00 \%$ of women, II $-66.67 \%$ and $33.33 \%$ respectively, III $-54.17 \%$ and $45.83 \%$ ). Young people predominated (respectively, group I - young $-60.00 \%$, middle $-35.00 \%$, elderly $-5.00 \%$; II - young $-79.17 \%$, middle $-20.83 \%$; III-young - $58,33 \%$, average $-33.33 \%$, elderly $-8.33 \%$ )

By genotype, patients with CVHC were evenly distributed: 1 b (group I $-55.00 \%$, II $-50.00 \%$, III $-54.17 \%$ ) and $3 a$ genotype (group I - 45, 00\%, II - 50,00\%, III -45,83\%). The degree of fibrosis F2 prevailed according to METAVIR (group I - 30.00\%, II - 37.50\%, III - 37.50\%), 1.6 times less people with fibrosis F0 (22, 06\%; I - 25.00\%, II - 25.00\%, III - 16.67\%), 2.0 times less patients with F1 (17.68\%; I $10.00 \%$, II $-20.83 \%$, III $-20.83 \%)$ and 2.7 times less often with F4 (13.24\%; I - 20.00\%, II - 8.33\%, III - 12.50\%) and in 3.0 - with F3 (11.76\%; I - 15.00\%, II - 8.33\%, I - 12.50\%).

Most patients had minimal activity $(80.88 \%$; I $-85.00 \%$, II $-70.83 \%$, III $-87.50 \%$ ), which is 4.2 times more than patients with moderate activity $(19.11 \%$; I $-15.00 \%$, II $29.17 \%$, III - 12.50\%). 
Clinical signs were dominated by asthenovegetative syndrome, severity of right hypochondrium and enlarged liver. All groups were representative of comorbidities. Diagnosed with diseases of the gastrointestinal tract (I - 20.00\%, II - 29.17\%; III - 25.00\%), heart failure (I - $10.00 \%$, II $-16.67 \%$, III $-12,50 \%)$, secondary arterial hypertension (I - 5.00\%, II - 12.50\%, III - 8.33\%), metabolic cardiomyopathy (I $-0.00 \%$, II $-12.50 \%$, III $4,17 \%)$, coronary heart disease (I - $10.00 \%$, II $-8.33 \%$, III $8.33 \%$ ), cardiofibrosis (I - 10.00\%, II - 8.33\%, III - 8.33\%), hypertension (I - 15.00\%, II - 4.17\%, III - 4.17\%), diabetes mellitus (I $-5.00 \%$, II $-4.17 \%$, III $-4.17 \%$ ), obesity (I $5.00 \%$, II $-4.17 \%$, III $-4.17 \%$ ), heart rhythm disorders (I $-0.00 \%$, II $-4.17 \%$, III $-4.17 \%$ ), cardiac disorders about idnosti (I - 5,00\%, II - 0,00\% and III - 4.17\%).

Among the hematological parameters in all groups of patients with CVHC there was a decrease in the number of platelets, compared with healthy individuals (healthy individuals - $234.50(196.75-270.00) \times 10^{9} / 1$, I - 197.00 (132.25 -234.75) x 109/1, II - $176.00(143.50-217.75) \times 10^{9} / 1$, III - $\left.178.50(146.75-231.50) \times 10^{9} / \mathrm{l}\right)(\mathrm{p}<0.05)$.

After 4 and 12 weeks of AVT in patients receiving PEGIFN and ribavirin, the number of leukocytes continued to decrease (before AVT - 4.68 (4.33-5.49) x 109/1, 4 weeks $3.403 .20-3.90) \times 10^{9} / 1,12$ weeks - 3.22(2.75-4.55) x 10 $\left./ 1\right)$, erythrocytes (respectively $5.09(4.56-5.34) \times 10^{12} / 1 ; 4.35$ $\left.(4.11-4.92) \times 10^{12} / \mathrm{l} ; 4.06(3.62-4.44) \times 10^{12} / \mathrm{l}\right)$, hemoglobin content (respectively $149.50(136.00-159.25) \mathrm{g} / \mathrm{l}, 130.00$ (124.25-136.75) g/l, $117.50(111.00-131.50) \mathrm{g} / \mathrm{l})$, platelets (respectively $176.00(143,50-217.75) \times 10^{9} / 1,150.50(128.00$ $\left.-173.00) \times 10^{9} / 1,143.00(122.75-159.50) \times 10^{9} / 1\right)(\mathrm{p}<0,05)$. The percentage of segmental neutrophils decreased at 4 weeks (40.00 (31.25-43.50)) compared to the values before the onset of AVT (47.00 (38.25-57.75)), but at 12 weeks their number increased ( $44.00(38.00-47.75))(\mathrm{p}<0.05)$. Also at 4 weeks the content of monocytes increased (from $6.50(6.00-9.75)$ to $10.00(8.00-11.00)$ ) and ESR (from $5.00(3.25-7.00)) \mathrm{mm} / \mathrm{h}$ to $13.50(6.00-17.00) \mathrm{mm} / \mathrm{h})$ ( $\mathrm{p}<0.05$ ), with 12 weeks the level of monocytes did not change (9.00 (7.00-12.00)), and ESR accelerated (18.00 $(7.50-24.75) \mathrm{mm} / \mathrm{h})(\mathrm{p}<0.05)$.

Among patients receiving sofosbuvir and velpatasvir, only the leukocyte formula changed at 4 weeks of AVT: segmental neutrophil counts decreased (from 51.50 (48.0055.75) to 47.50 (39.25-53.25)) and ESR increased (from 6.00 $(5.00-9.75) \mathrm{mm} / \mathrm{h}$ to $12.50(7.25-19.50) \mathrm{mm} / \mathrm{h})(\mathrm{p}<0.05)$ at 12 weeks. AVT decreased the number of erythrocytes compared with 4 weeks (from 4.63 (4.14-5.03) x $10^{12} / 1$ to $\left.4.20(3.98-4.33) \times 10^{12} / 1\right)$ and hemoglobin (from 141.50 (134.50-153.75) g / 1 to $134.00(126.00-140.00) \mathrm{g} / 1)$, the number of platelets increased from $182.50(152.00-247.50)$ x $10^{9} / 1$ to $\left.193.50(159.00-208.25) \times 10^{9} / \mathrm{l}\right)(\mathrm{p}<0.05)$.

In all groups of patients with CVHC there was an increase in the activity of ALT, AST, GGTP, alkaline phosphatase $(\mathrm{AlPh})$ in the biochemical analysis of blood compared with healthy individuals $(\mathrm{p}<0.05)$. At 4 and 12 weeks of AVT in groups II and III there was a decrease in ALT (II - before the AVT - 77.50 (36.00-121.75), 4 weeks -
48.00 (29.25-82.00), 12 weeks - 24.00 (16.00-43.50), III - respectively 65.00 (44.25-106.00), 24.00 (20.00-41.75), 22.50 (19, 00-33.50)); AST (II - before the onset of AVT - 56.00 (36.00-75.25), 4 weeks - 41.50 (27.75-53.00), 12 weeks - 29.00 (21.50- 39.00), III - respectively 54.50 (39.25-62.00), 24.00 (20.25-29.75), 24.50 (21.00-33.75)) $(\mathrm{p}<0.05)$. Patients with the interferon-containing scheme of AVT experienced GGT a decrease (before the beginning of AVT - 40.00 (22.50-66.25), 4 weeks - 32.00 (24.00-60.00), 12 weeks - 24.00 (20.25-33.00)), and in patients receiving DAAs for 4 weeks an increase (from 36.00 (24.25-53.25) to $44.50(28.50-64.00))$, and a decrease again by $12(33.00$ $(21.00-72.75))(\mathrm{p}<0.05)$. Total bilirubin in infected of group II at 4 weeks increased (from 15.05 (9.53-27.20) $\mu \mathrm{mol} / \mathrm{l}$ to $25.10(15.45-29.25(\mu \mathrm{mol} / \mathrm{l}))$, and at 12 weeks decreased $(15.20(12.18-22.23) \mu \mathrm{mol} / \mathrm{l})$, while in patients with group III bilirubin levels at 4 and 12 weeks gradually decreased (by the onset of AVT 19,45 (15,40-24,83) $\mu \mathrm{mol} /$ l, 4 weeks - 14,85 $(9,75-17,95) \mu \mathrm{mol} / \mathrm{l}, 12$ weeks - 14.00 $(12,33-19.38) \mu \mathrm{mol} / \mathrm{l}(\mathrm{p}<0.05)$.

The dynamics of changes in integrative indicators had both common trends and differences in patients treated according to different schemes. Patients who received interferoncontaining AVT at 4 and 12 weeks of treatment, compared with data before treatment, had increased value of ISI (before AVT - 13.82 (13.64-14.16), 4 weeks - 14.91 (13.90- 15.62), 12 weeks - 15.48 (14.13-16.36)), decreased entropy of leukocyte formula at 4 weeks (from 26.12 (19.09-33.90) to 22.15 (20, 79-23.70), $\mathrm{p}<0.05$ ). In patients treated with velpatasvir and sofosbuvir for 4 weeks, only the value of ISI increased from 13.95 (13.82-14.41) to $14.76(14.10-15.62), \mathrm{p}<0.05)$.

Among the indices of nonspecific reactivity in patients from group II at 4 weeks was observed increased RC (from $0.67(0.53-0.82)$ to $1.12(0.94-1.63)$ ), Ilymph (from 0.63 ) $0.46-0.92)$ to 1.02 (0.86-1.43), NI (from 0.05 (0.04-0.08) to 0.12 (0.07-0.17)), but at 12 weeks decreased compared to the previous value and normalized - RC $(0.90(0.74-1.26))$ and Ilymph $(0.78(0.66-1.09)))(\mathrm{p}<0.05)$ At the same stage in these patients decreased LMR (from 7.39 (5.29-9.42) to $4.45(3.85-5.69)$ ) and ELR (from $0.06(0.03)-0.11)$ to 0.02 $(0.00-0.04))(\mathrm{p}<0.05)$. In patients of group III at 4 weeks increased CR (from 0.67 (0.53-0.82)) to 0.85 (0.57-1.13)), IR (from 4.94 (3.57-7.35) to 5.92 (4.50-9.45)), ELR (from 4,65 (3.44-7.10) to 5.67 (3.83-9.09)), but at 12 weeks these integrative indicators decreased (respectively $0.66(0.56-$ $0.75) ; 3.74$ (2.79-4.94); $3.48(2.69-4.88))(\mathrm{p}<0.05)$.

The dynamics of changes in the indices of inflammatory activity was the same in groups II and III: at 4 weeks of AVT increased ILG (II - from 6.06 (4.54-8.71) to 9.77 (8.2413.90), III - from 6.02 (4.70-7.42) to 7,45 (5.29-10.11)); IL ESR (II - from 1.69 (1.00-2.87) to 6.01 (2.54-8.17); III - from 2.08 (1.56-3.26) to 4, 71 (2.66-7.11)), and decreased only KI (II - from 1.59 (1.08-2.18) to 0.98 (0.70-1.16); III - from 1.64 $(1.29-2.08)$ to $1.26(0.92-1.80))(\mathrm{p}<0.05)$. At 12 weeks of AVT in these patients was observed on the contrary decrease in ILG (II - up to 7.42 (6.56-10.90); III - up to 5.74 (4.92-6.86)) and increase in KI (II - up to 1, 27 (0.92-1.51); III - up to 1.63 (1.43-1.96)) compared with 4 weeks ( $\mathrm{p}<0.05)$. 
Table I. The concentration of galectin-9 in the serum of patients with CVHC with different variants of AVT

\begin{tabular}{|c|c|}
\hline Group & Galectin-9 (pg/ml) \\
\hline Comparison $(n=20)$ & $1747,90(966,45-3241,50)$ \\
\hline I (baseline therapy, n=20) & $\begin{array}{c}3006,00(1754,60-4639,50) \\
\left(p_{1}=0,040^{*}\right)\end{array}$ \\
\hline II (IFN ribavirin, after 4 weeks of AVT, $n=24$ ) & $\begin{array}{c}7267,00(3633,50-11955,50) \\
\left(p_{1}=0,000^{*} ;\right. \\
\left.p_{2}=0,000^{* *}\right)\end{array}$ \\
\hline III (DAAs, after 4 weeks of AVT, $n=24$ ) & $\begin{array}{c}2227,00(1544,30-2639,00) \\
\left(p_{1}=0,444 ;\right. \\
p_{2}=0,073 ; \\
\left.p_{3}=0,000^{* * *}\right)\end{array}$ \\
\hline
\end{tabular}

Note. Significant difference of the indicator in relation to: ${ }^{*}$ - comparison groups $(\mathrm{p} 1<0.05) ;{ }^{* *}$ - groups of patients who did not receive AVT $(\mathrm{p} 2<0.05)$, *** - groups II and III among themselves (p3<0.05), significance was calculated according to the Mann-Whitney criterion

Indices of endogenous intoxication in patients receiving interferon-containing AVT changed as follows: at 4 weeks decreased LSI (from 1.34 (0.93-1.76) to 0.83 (0.59-1.00)), NRR (from 3,66 (2.02-11.88) to $2.50(0.00-4.97)$ ), but at 12 weeks increased LSI (up to $1.07(0.79-1.26)$ ), NRR to $3.05(0.00-11.59)$ ), IIS (from $0.20(0.12-0.23)$ to 0.37 (0.12$0.62)$ ). At patients on the interferon-free scheme at 4 weeks of changes in comparison with the beginning of treatment did not occur, and at 12 weeks in comparison with 4 weeks the level of LII increased (from $0,44(0,28-0,78)$ to 0,83 (0,45- 1.23)), Iagr (from $0.59(0.39-1.04)$ to $1.16(0.59$ 1.63)), HII (from $0.52(0.28-0.87))$ to $0.98(0.45-1.56)$ ), IIS (from $0.28(0.12-0.55)$ to $0.63(0.22-1.19)$ ).

The level of galectin-9 was determined in all patients. In patients who did not receive AVT, the concentration of galectin-9 was 1.7 times higher than in healthy individuals (Table I). The amount of galectin-9 in individuals receiving interferon-containing AVT was 4.2 times higher than in healthy patients; 3.3 times higher than those who received DAAs; and 2.4 times higher for patients who did not receive AVT. Among patients receiving DAAs, galectin-9 levels did not differ from healthy individuals, but tended to decrease compared with patients without AVT.

In CVHC patients who did not receive AVT, as well as in healthy individuals, no correlation was found between galectin- 9 concentration and age, gender, and between genotype and process activity ( $\mathrm{p}>0.05)$.

According to the results of ROC-analysis among all clinical data in patients with CVHC, the highest diagnostic value was established to determine the presence of splenomegaly from the level of galectin-9 (AUC $=0.944$ $(\mathrm{p}<0.05))$ (Fig. 1). To verify the presence of splenomegaly we determined the limit level of galectin-9 in the serum (cut of value). Thus, the cut-off level of lectin was 4829 pg / ml (sensitivity (Se) - 100\%, specificity (Sp) $88.9 \%)$. According to all other clinical data, no reliable asymptomatic significance was obtained ( $p>0.05)$.

Among patients treated with PEG-IFN and ribavirin during ROC analysis of autoimmune parameters (ANA, AMA, ATPO, ATTG) and lectin levels, it was found that the higher the level of galectin- 9 at 4 weeks of AVT, the greater probability of detecting positive ANA at 12 weeks of treatment (AUC = $0.773(\mathrm{p}=0.032)$ (Fig. 2). The cut-off threshold for CGal-9 was $8360 \mathrm{pg} / \mathrm{ml}$ (Se $-75.0 \%$, Sp - 68.7\%).

When calculating the correlations between the level of galectin-9 and hematological parameters in healthy individuals, an inversely proportional connection was found between the level of lectin and the number of rodshaped neutrophils (Table II). In patients not receiving AVT, an inverse correlation was observed between galectin-9 concentration and platelet count. The same correlation was observed in patients receiving an interferoncontaining regimen after 4 weeks of treatment, but no correlation was observed between these values at 12 weeks after the onset of AVT. Between the amount of galectin-9 at 4 weeks of AVT and the neutrophil count at 12 weeks of AVT revealed an inversely proportional relationship, and a direct relationship between the level of lectin and basophils.

Among CVHC patients who did not receive AVT, a directly proportional correlation was found between the concentration of galectin- 9 and the De Ritis ratio $(+0.448$, $p=0.048)$, and the tendency to correlate between these indicators in healthy individuals $(+0.391, \mathrm{p}=0.088)$, which may indicate a significantly higher hepatocellular insufficiency, with a higher level of lectin of the patient. In infected patients who did not receive AVT, there was a tendency to correlate the amount of galectin- 9 with AST activity, in patients receiving PEG-IFN and ribavirin at 4 weeks - with GGT activity, in those treated with velpatasvir and sofosbuvir at 4 weeks - with the amount of total protein, at 12 weeks - with ALT activity (Table III).

During the study of correlations between the amount of galectin-9 in blood serum and integrative indicators in the comparison group, inversely proportional relationship between the concentration of lectin and NI, TII, NRR $(p<0,05)$, which indicates a decrease in the degree of its own inflammatory response organism and reduction of endogenous intoxication with increasing galectin-9 in healthy individuals was found.

In patients receiving baseline therapy, no significant correlations were found, but there was a tendency to reduce the rate of intoxication with increasing galectin-9 (Fig. 3), which indicates a weakening of the systemic immune response to acute inflammation. 


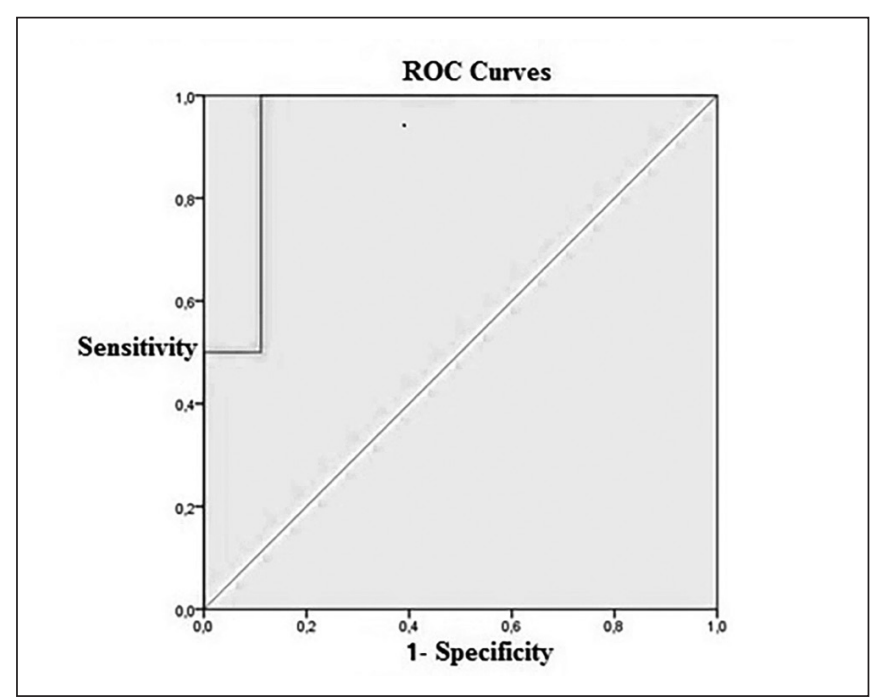

Fig. 1. Prediction of the development of splenomegaly by the concentration of galectin- 9 in the serum of patients with CVHC ROC Curves

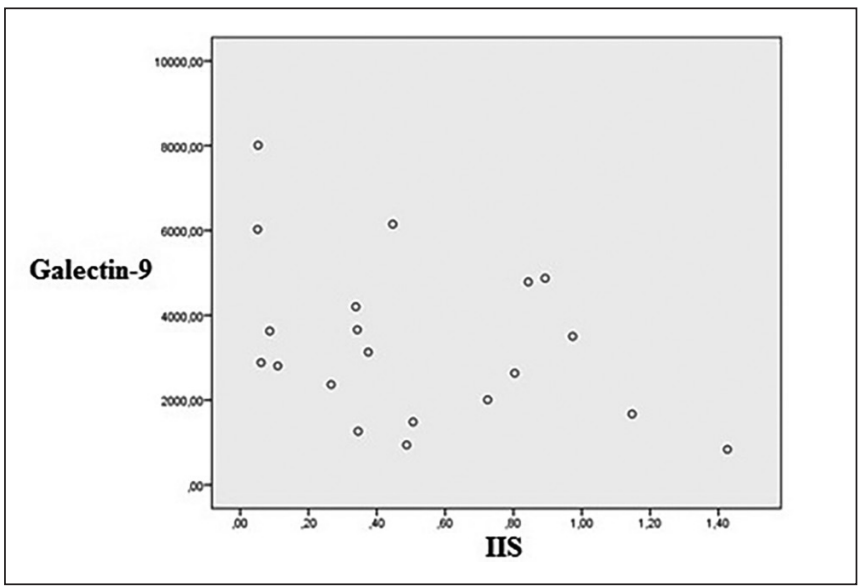

Fig. 3. Approximation to the correlation between galectin-9 concentration and intoxication in CVHC patients who did not receive AVT. * Note: the tendency to correlate indicators is inversely proportional $(r=-0.389, p=0.090$; calculated according to Spearman's correlation).

In patients receiving PEG-IFN and ribavirin, there were no correlations between galectin-9, which was determined at 4 weeks of AVT, and integrative values at 4 weeks of treatment, but there was a connection between the amount of lectin at 4 weeks and NI at 12 weeks of AVT (Fig. 4). It allows to predict a decrease in the inflammatory response in the patient's body after 12 weeks with high levels of galectin-9 after a month of treatment.

Among patients treated with DAAs at 4 weeks of AVT, there was a tendency for a directly proportional correlation between galectin- 9 levels in serum and the rate of intoxication (Fig. 5), which illustrates an increase in the systemic inflammatory response with increasing lectin concentration, in contrast to untreated patients.

In addition, among patients receiving velpatasvir and sofasbuvir, there was a tendency to correlate between galectin-9 at 4 weeks and the entropy of the leukocyte formula at 12 weeks of AVT (Fig. 6), which suggests a tendency to more pronounced normalization of the

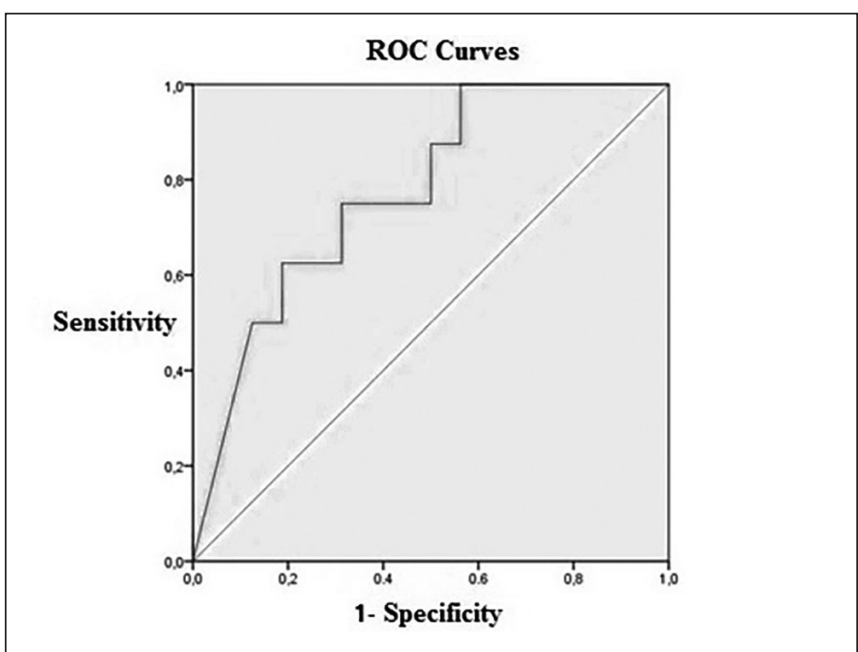

Fig. 2. Prediction of changes in ANA by the concentration of galectin-9 in the serum of patients with CVHC at 4 weeks of interferon-containing AVT, ROC Curves

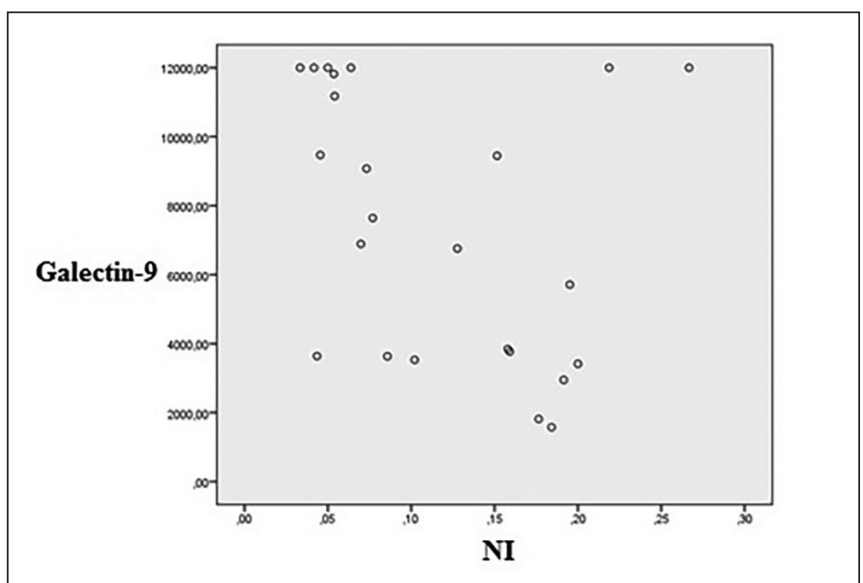

Fig. 4. Correlation between galectin- 9 concentration at 4 weeks of AVT and nuclear index after 12 weeks of AVT in patients on interferon-containing therapy * Note: The correlation of indicators is inversely proportional $(r=-0.424$, $\mathrm{p}=0.039$; calculated according to Spearman's correlation)

leukocyte formula at 12 weeks with a lower value of galectin-9 for 4 weeks of treatment.

In CVHC patients who did not receive AVT, when calculating the correlations between the detected lectin and fibrosis (F) by METAVIR, there was an increase in the amount of galectin- 9 with increasing degree of fibrosis $(+0.550$; $p=$ 0.012 ). Directly proportional correlation was found for the content of galectin-9 and APRI (Fig. $7 ;+0.505 ; p=0.023$ ) and galectin-9 and FIB-4 (Fig. 8; +0.448; $\mathrm{p}=0.048$ ).

ROC analysis for CGal-9 and liver cirrhosis in patients not receiving AVT demonstrated a high probability of liver cirrhosis with galectin- 9 content above $3929 \mathrm{pg} / \mathrm{ml}($ AUC $=$ 0.813 ; sensitivity $-75.0 \%$, specificity $-81.2 \%$, Fig. 9).

\section{DISCUSSION}

The amount of galectin-9 in patients receiving interferoncontaining AVT was 4.2 times higher than in healthy indi- 
Table II. Correlations between galectin-9 concentration and hematological parameters

\begin{tabular}{|c|c|c|c|c|c|c|}
\hline \multirow[b]{3}{*}{ Indicator } & \multicolumn{6}{|c|}{ The concentration of galectin- 9 in the group, (n), the survey period } \\
\hline & \multirow[b]{2}{*}{$\begin{array}{c}\text { Comparison } \\
(n=20)\end{array}$} & \multirow[b]{2}{*}{$I(n=20)$} & \multicolumn{2}{|c|}{ II ( $n=24,4$ week of AVT) } & \multicolumn{2}{|c|}{ III (n=24, 4 week of AVT) } \\
\hline & & & $\begin{array}{c}\text { With } \\
\text { hematological } \\
\text { parameters at } 4 \\
\text { weeks of AVT }\end{array}$ & $\begin{array}{c}\text { With } \\
\text { hematological } \\
\text { parameters at } 12 \\
\text { weeks of AVT }\end{array}$ & $\begin{array}{c}\text { With } \\
\text { hematological } \\
\text { parameters at } 4 \\
\text { weeks of AVT }\end{array}$ & $\begin{array}{c}\text { With } \\
\text { hematological } \\
\text { parameters at } \\
12 \text { weeks of AVT }\end{array}$ \\
\hline Leukocytes & $\begin{array}{c}-0,280 \\
p=0,232\end{array}$ & $-0,239, p=0,310$ & $+0,392, p=0,058$ & $-0,027, p=0,900$ & $+0,190, p=0,374$ & $+0,097, p=0,650$ \\
\hline Erythrocytes & $\begin{array}{c}+0,381, \\
p=0,098\end{array}$ & $+0,084, p=0,724$ & $-0,286, p=0,175$ & $-0,119, p=0,930$ & $-0,073, p=0,734$ & $+0,091, p=0,674$ \\
\hline Hemoglobin & $\begin{array}{l}+0,399 \\
p=0,081\end{array}$ & $-0,091, p=0,703$ & $-0,336, p=0,108$ & $+0,002, p=0,928$ & $+0,186, p=0,383$ & $+0,064, p=0,776$ \\
\hline Platelets & $\begin{array}{c}-0,249 \\
p=0,290\end{array}$ & $-0,531, p=0,016^{*}$ & $-0,429, p=0,036^{*}$ & $-0,126, p=0,557$ & $+0,015, p=0,945$ & $-0,255, p=0,259$ \\
\hline Rod-core & $\begin{array}{c}-0,538, \\
p=0,014^{*}\end{array}$ & $+0,044, p=0,855$ & $+0,108, p=0,615$ & $-0,536, p=0,007^{*}$ & $-0,078, p=0,717$ & $-0,084, p=0,696$ \\
\hline $\begin{array}{l}\text { Segment- } \\
\text { nuclear }\end{array}$ & $\begin{array}{c}-0,105 \\
p=0,661\end{array}$ & $-0,093, p=0,698$ & $-0,171, p=0,426$ & $-0,091, p=0,673$ & $+0,105, p=0,627$ & $+0,316, p=0,133$ \\
\hline Eosinophils & $\begin{array}{c}-0,260 \\
p=0,269\end{array}$ & $+0,220, p=0,352$ & $-0,130, p=0,544$ & $+0,046, p=0,832$ & $-0,347, p=0,145$ & $-0,127, p=0,555$ \\
\hline Basophils & $\begin{array}{c}-0,195 \\
p=0,410\end{array}$ & $+0,134, p=0,574$ & $+0,125, p=0,559$ & $+0,413, p=0,045^{*}$ & $-0,156, p=0,359$ & $+0,446, p=0,029^{*}$ \\
\hline Lymphocytes & $\begin{array}{c}+0,260 \\
p=0,269\end{array}$ & $+0,112, p=0,637$ & $+0,074, p=0,731$ & $-0,038, p=0,859$ & $+0,004, p=0,985$ & $-0,171, p=0,425$ \\
\hline Monocytes & $\begin{array}{c}-0,190 \\
p=0,422\end{array}$ & $-0,151, p=0,524$ & $-0,023, p=0,916$ & $+0,211, p=0,322$ & $-0,176, p=0,409$ & $-0,238, p=0,263$ \\
\hline ESR & $\begin{array}{c}-0,102 \\
p=0,668\end{array}$ & $+0,234, p=0,321$ & $+0,128, p=0,553$ & $-0,113, p=0,598$ & $+0,125, p=0,561$ & $+0,270, p=0,202$ \\
\hline
\end{tabular}

Note. * - significant correlation of galectin-9 with the corresponding indicator ( $p<0.05$, calculated according to Spearman's correlation).

viduals; compared to patients who received DAAs - 3.3 times higher; and compared with patients who did not receive AVT - 2.4 times higher. It is known from literature that recombinant human galectin-9 induces the production of interferon, and blocking the synthesis of galectin- 9 reduces the amount of interferon produced by natural killers stimulated by IL-12 / IL-15 [8]. In addition, treatment of liver and peripheral blood mononuclear cells with galectin-9 induces the production of proinflammatory cytokines, including IL-1, TNF-a and IFN [9]. In patients with autoimmune cholangitis when studying the expression of galectin-1, galectin-3 and galectin-9, a significant increase in the latter was found after stimulation of gamma-IFN [10]. Based on this, we talk about the bilateral effects of galectin-9 and IFN.

Among patients with CVHC, a directly proportional correlation was found between the content of galectin- 9 and F (METAVIR), APRI and FIB-4. In patients with different etiologies of chronic hepatitis, according to previous studies, a direct proportional correlation between the concentration of this lectin and APRI, FIB-4 was also determined [11]. It is proven that the expression of galectin-9/Tim-3 serves as a useful prognostic marker in patients with hepatocellular carcinoma [12], while it is most often detected in the third stage of fibrosis and in patients with cirrhosis [13].
An inversely proportional correlation between the level of lectin and the number of rod-shaped neutrophils was found in the comparison group between the level of galectin-9 and hematological parameters. Experiments on mice have shown that exogenous galectin- 9 reduces local tissue infiltration by inflammatory cells, including neutrophils [14]. There was an inverse correlation between the concentration of galectin-9 and platelet count in patients who did not receive AVT and at 4 weeks of treatment in patients receiving interferon-containing therapy. According to previous scientific studies, an inverse correlation has been established in patients with various chronic hepatitis (including CVHC) between galectin-9 and platelet count [11].

It was determined that among CVHC patients who did not receive AVT, a directly proportional correlation was found between the concentration of galectin- 9 and the De Ritis ratio, as well as the tendency to correlate between these indicators in healthy individuals, which corresponds to the results of other researchers, where it is indicated that patients with hepatocellular failure have higher levels of galectin-9 in plasma than in the control group [15].

In our study, we established a tendency in patients who did not receive AVT to correlate between the amount of galectin- 9 


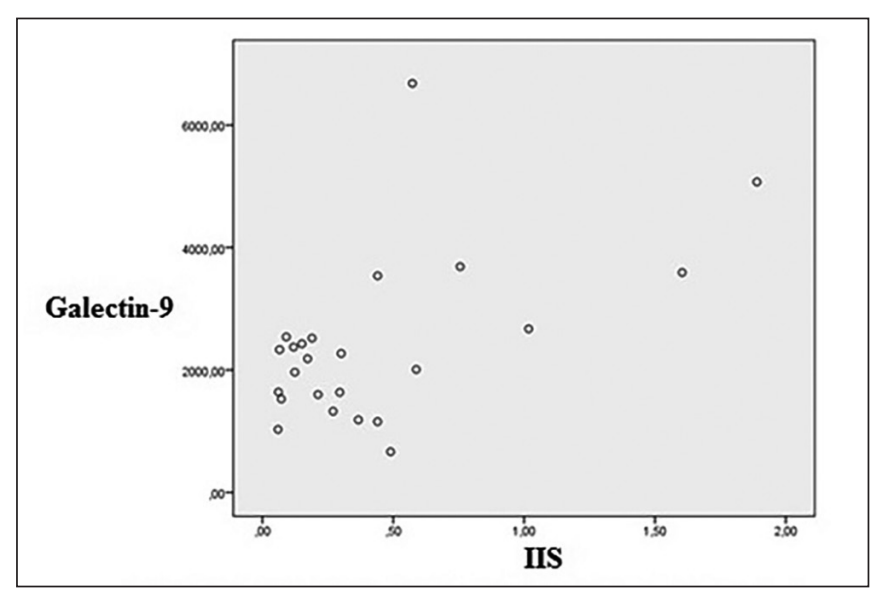

Fig. 5. Approximation to the correlation between galectin-9 concentration and 4 weeks of AVT intoxication in patients on interferon-free therapy * Note: The correlation of indicators is directly proportional $(r=+0.403$, $p=0.051$; calculated according to Spearman's correlation)

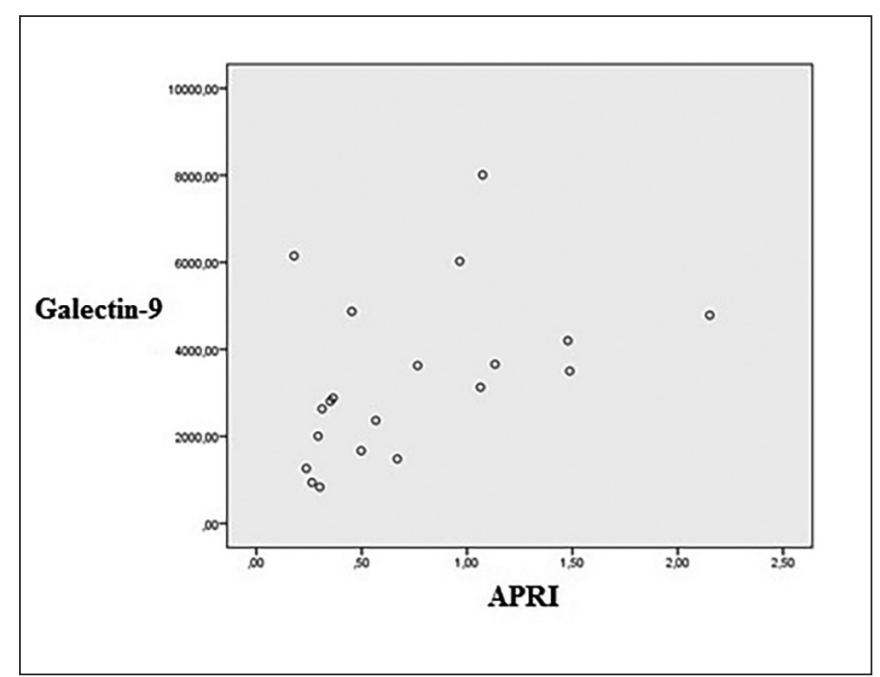

Fig. 7. Correlation between galactin- 9 concentration and APRI.

and ACT activity; in patients receiving PEG-IFN and ribavirin for 4 weeks - with GGT activity; in infected patients treated with velpatasvir and sofosbuvir for 4 weeks - with the amount of total protein for 12 weeks - with ALT activity. In other publications in chronic hepatitis of various genesis (caused by HCV, HBV, autoimmune, alcoholic) was found a weak correlation with the activity of ALT $[12,14]$. The high level of enzymes (including ALT) in the blood of patients with elevated concentrations of galectin-9 is due to the fact that the hepatocyte infected with $\mathrm{HCV}$ on the outer membrane is phosphatidylserine, which is recognized by Kupffer cells. Further, these specific liver macrophages secrete galectin-9, which activates naive NKs that destroy hepatocytes, thereby exacerbating the cytolytic syndrome [3].

According to scientific studies, the concentration of galectin-9 in patients with autoimmune hepatitis exceeds the level of this lectin in patients with CVHC [16], despite the fact that in the pathogenesis of viral hepatitis $\mathrm{C} \mathrm{a}$ significant place is occupied by autoimmune mechanisms [17]. When other researchers studied the effects of galectin-9 in laboratory mice, it was found that in animals deficient

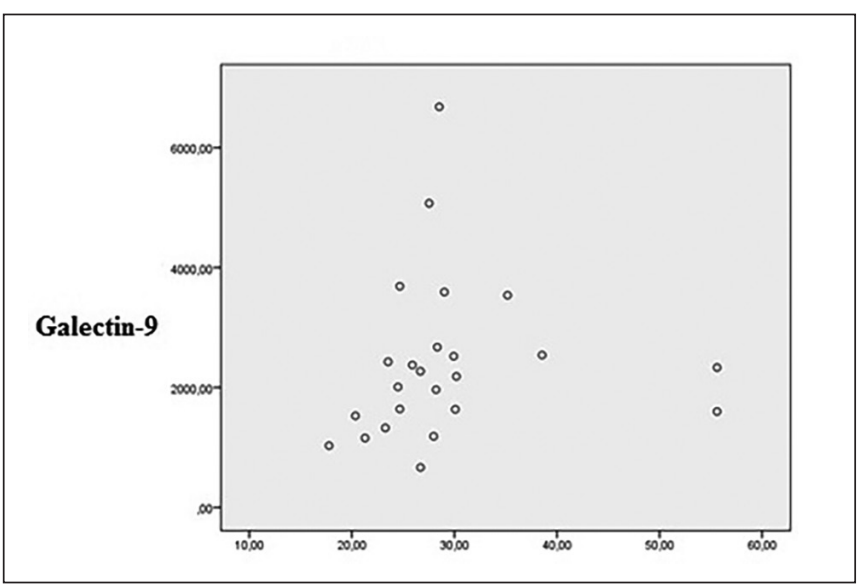

Fig. 6. Approximation to the correlation between galectin-9 concentration and 4 weeks of AVT and the entropy of the leukocyte formula at 12 weeks of AVT in patients on interferon-free therapy *Note: The correlation of indicators is directly proportional $(r=+0.396$, $p=0.055$; calculated according to Spearman's correlation)

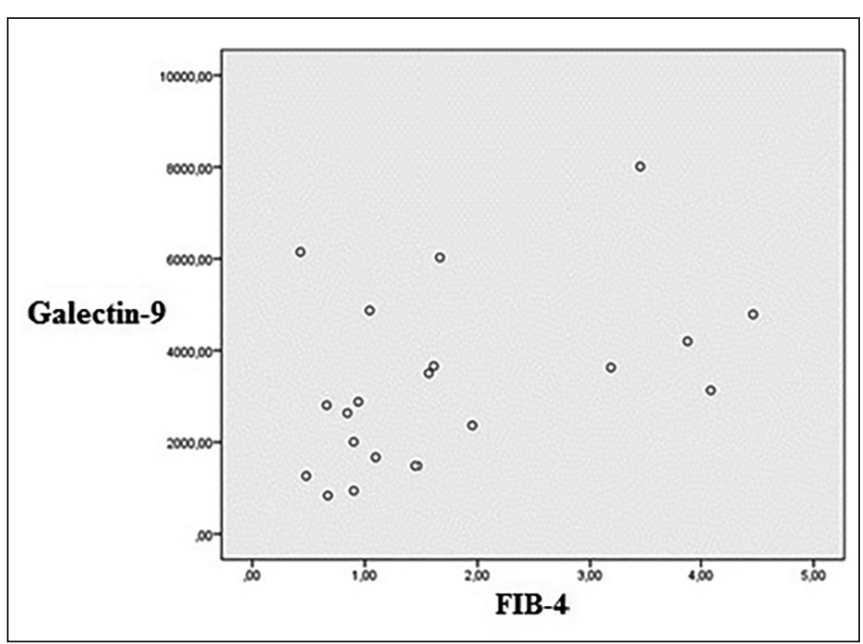

Fig. 8. Correlation between galactin-9 concentration and FIB-4

in this protein there was an increase in the number of T-helpers and a decrease in the number of T-suppressors. In addition, treatment with galectin-9 naive T-cells in vitro also promotes the differentiation of regulatory $\mathrm{T}$ lymphocytes and inhibits the differentiation of $\mathrm{T}$ helpers, which leads to immunosuppression [18]. Among our patients treated with PEG-IFN and ribavirin, it was found that the higher the level of galectin- 9 at 4 weeks of AVT, the greater the likelihood of positive ANA at 12 weeks of treatment, indicating differences between galectin levels and antibodies in individuals receiving interferon-containing therapy and the mechanisms described above. This is due to the results of the following study, which proved that IFN-based treatment reduces the proportion of regulatory T-cells after 4 weeks in therapy, due to a decrease in IL-12. Thus, early depletion of regulatory T-cells caused by IFN promotes the activation of antiviral immunity [19], but does not weaken autoimmune reactions.

Among our patients, there was a tendency to decreasing the rate of intoxication with increasing galectin-9, which indicates a decrease in the intensity of the acute 
Table III. Correlations between galectin-9 concentration and biochemical parameters

\begin{tabular}{|c|c|c|c|c|c|c|}
\hline \multirow[b]{3}{*}{ Indicator } & \multicolumn{6}{|c|}{ The concentration of galectin- 9 in the group, $(n)$, the survey period } \\
\hline & \multirow[b]{2}{*}{$\begin{array}{l}\text { Comparison } \\
(n=20)\end{array}$} & \multirow[b]{2}{*}{$I(n=20)$} & \multicolumn{2}{|c|}{ II ( $n=24,4$ week of AVT) } & \multicolumn{2}{|c|}{ III (n=24, 4 week of AVT) } \\
\hline & & & $\begin{array}{c}\text { With } \\
\text { biochemical } \\
\text { parameters at } 4 \\
\text { weeks of AVT }\end{array}$ & $\begin{array}{c}\text { With } \\
\text { biochemical } \\
\text { parameters at } \\
12 \text { weeks of AVT }\end{array}$ & $\begin{array}{c}\text { With } \\
\text { biochemical } \\
\text { parameters at } 4 \\
\text { weeks of AVT }\end{array}$ & $\begin{array}{c}\text { With } \\
\text { biochemical } \\
\text { parameters at } \\
12 \text { weeks of AVT }\end{array}$ \\
\hline Total protein & $-0,058, p=0,808$ & $+0,083, p=0,729$ & $-0,048, p=0,822$ & $-0,335, p=0,110$ & $-0,365, p=0,079$ & $-0,047, p=0,827$ \\
\hline Total bilirubin & $+0,057, p=0,811$ & $+0,006, p=0,980$ & $-0,286, p=0,175$ & $-0,287, p=0,174$ & $-0,013, p=0,952$ & $+0,134, p=0,531$ \\
\hline ALT & $-0,211, p=0,372$ & $-0,052, p=0,828$ & $+0,248, p=0,243$ & $-0,237, p=0,265$ & $+0,009, p=0,969$ & $+0,357, p=0,087$ \\
\hline AST & $+0,169, p=0,477$ & $+0,390, p=0,089$ & $-0,193, p=0,363$ & $-0,169, p=0,431$ & $+0,181, p=0,395$ & $+0,225, p=0,291$ \\
\hline GGTP & $-0,032, p=0,892$ & $+0,259, p=0,270$ & $+0,367, p=0,078$ & $+0,149, p=0,487$ & $-0,030, p=0,888$ & $+0,160, p=0,454$ \\
\hline ALP & $+0,370, p=0,108$ & $-0,146, p=0,139$ & $+0,074, p=0,731$ & $+0,183, p=0,391$ & $+0,176, p=0,410$ & $-0,130, p=0,544$ \\
\hline Creatinine & $+0,255, p=0,278$ & $+0,153, p=0,520$ & $+0,012, p=0,755$ & $-0,037, p=0,863$ & $-0,074, p=0,733$ & $-0,033, p=0,880$ \\
\hline Glucose & $+0,110, p=0,646$ & $+0,030, p=0,899$ & $+0,114, p=0,595$ & $-0,121, p=0,574$ & $+0,089, p=0,702$ & $-0,102, p=0,636$ \\
\hline
\end{tabular}

Note. ${ }^{*}$ - significant correlation of galectin- 9 with the corresponding indicator ( $p<0.05$, calculated according to the Spearman's correlation)

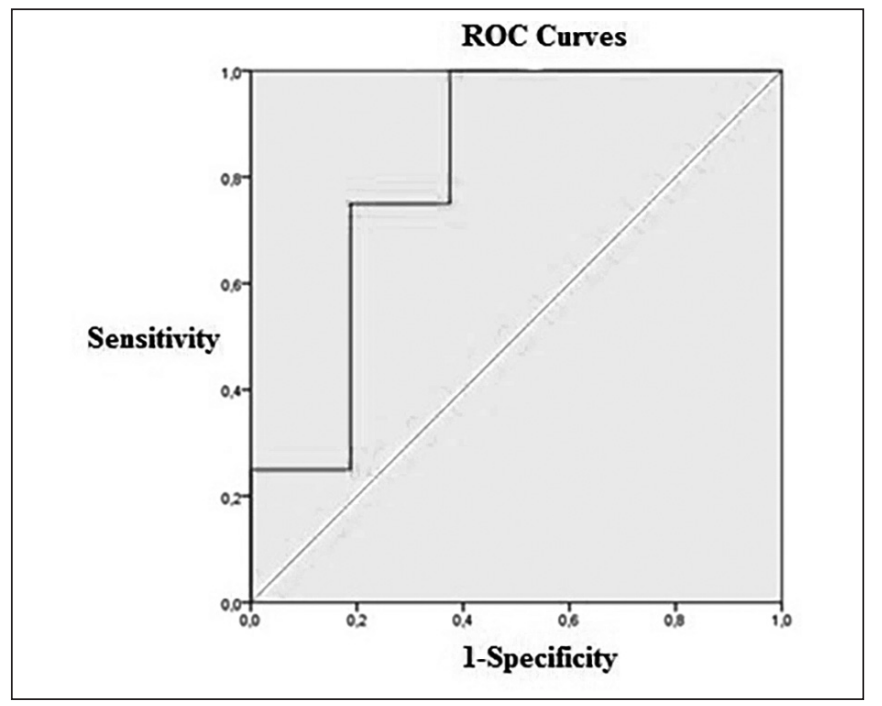

Fig. 9. Prediction of liver cirrhosis by the concentration of galectin- 9 in the serum of patients with CVHC

inflammatory process and the weakening of the systemic immune response to it [20]

In patients receiving PEG-IFN and ribavirin, an inverse correlation was observed between the amount of galectin-9 at 4 weeks and NI at 12 weeks of AVT. It allows predicting a decrease in the inflammatory response in the patient's body after 12 weeks, with high levels of galectin-9 after a month of treatment [5].

\section{CONCLUSIONS}

Male young patients with moderate fibrosis, $1 \mathrm{~b}$ genotype and minimal activity predominate with CVHC.

HCV-infected patients have higher levels of galectin-9 compared to healthy individuals $(\mathrm{p}<0.05)$. Usage of PEG-IFN and ribavirin in the treatment significantly increases the lectin content in patients with CVHC $(\mathrm{p}<0.05)$. There is a tendency of CGal-9 decreasing under the influence of sofosbuvir and velpatasvir, compared with patients without AVT.

The increase in Gal-9 concentration correlates with an increase in F indicators (METAVIR), APRI, FIB-4, De Ritis ratio and a decrease in platelet count $(\mathrm{p}<0,05)$, which proves the feasibility of determining the amount of lectin in the serum of patients with CVHC to establish liver fibrosis and hepatic insufficiency.

The inversely proportional correlation between CGal-9 at week 4 of interferon-containing AVT and NI at week 12 predicts the severity of the inflammatory response in CVHC patients during treatment.

At the Gal-9 concentration above $8360 \mathrm{pg} / \mathrm{l}$ at 4 weeks of interferon-containing AVT one should take into account the high probability of autoimmune processes, which is confirmed by the detection of positive ANA at 12 weeks (Se - 75.0\%, Sp - 68.7\%). In patients who did not receive AVT, when CGal-9 is above $3929 \mathrm{pg} / \mathrm{ml}$ liver cirrhosis (Se $-75.0 \%, \mathrm{Sp}-81.2 \%)$ may be estimated, and if it is above $4829 \mathrm{pg} / \mathrm{ml}$ - splenomegaly (Se - $100.0 \%$, Sp - 88.9\%).

\section{REFERENCES}

1. Kofahi H.M., Taylor N.G., Hirasawa K. et al. Hepatitis C virus infection of cultured human hepatoma cells causes apoptosis and pyroptosis in both infected and bystander cells. Sci Rep. 2016; 6: 37433.

2. Lim E.J., El Khobar K., Chin R. et al. Hepatitis C virus induced hepatocyte cell death and protection by inhibition of apoptosis. J Gen Virol. 2014 ; 95: 2204-15.

3. Zahaf A., Badia A., Morel J., Dellis 0. Gal-9 promotes viral persistence of hepatitis virus in the liver. Med Sci (Paris). 2017;33(11): 947-9.

4. Harwood N. M. K., Golden-Mason L. et al.. HCV-infected cells and diff erentiation increase monocyte immunoregulatory galectin-9 production. Journal of Leukocyte Biology. 2017; 99 (3): 495-503.

5. Hodlevs'kyy A. I., Savolyuk S. I. Diahnostyka ta monitorynh endotoksykozu u khirurhichnykh khvorykh: monohrafiya [Diagnosis and monitoring of endotoxicosis in surgical patients: monograph]. Vinnytsya: Nova Knyha. 2015; 232. http://lib.inmeds.com.ua:8080/jspui/ bitstream/lib/3321/1/Diagnostika_ta_monitoring_endotoksikoza. pdf. (in Ukrainian). 
6. Kuznetsov P. L., Borzunov V. M. Syndrom éndohennoy yntoksykatsyy v patoheneze vyrusnoho hepatyta [Endogenous intoxication syndrome in the pathogenesis of viral hepatitis]. Éksperymental'naya y klynycheskaya hastroénterolohyya. 2013; 4: 44-50. (in Russian).

7. Khokhlova N. I., Tolokonskaya N. P., Pupyshev A. B. et al. Multifactorial evaluation ofendogenousintoxicationin patientswithchronicviralhepatitis C. Klinichescheskaya Laboratornaya Diagnostika. 2010; 8: 30-33.

8. Lai J. H., Luo S. F., Wang M. Y. et al.. Translational Implication of Galectin-9 in the Pathogenesis and Treatment ofViral Infection. International Journal of Molecular Sciences. 2017; 18 (10). doi:10.3390/ijms18102108.

9. Mengshol J.A., Golden-Mason L., Arikawa T. et al. Acrucial role for Kupff er cell-derived galectin- 9 in regulation of $\mathrm{T}$ cell immunity in hepatitis $\mathrm{C}$ infection. LoS One. 2010; 5: e9504.

10. Fan J., Tang X., Wang Q. et al. Mesenchymal stem cells alleviate experimental autoimmune cholangitis through immunosuppression and cytoprotective function mediated by galectin- 9 . Stem Cell Res Th er . 2018; 9 (1).

11. Fujita K., Niki T., Nomura T. et al.. Correlation between serum galectin-9 levels and liver fibrosis. Journal of Gastroenterology and Hepatology. 2018; 33: 492-99.

12. Li H., Wu K., Tao K. et al.. Tim-3/galectin-9 signaling pathway mediates $\mathrm{T}$ cell dysfunction and predicts poor prognosis in patients with HBVassociated hepatocellular carcinoma. Hepatology. 2012; 56: 1342-51.

13. Zhang D.Y., Friedman S.L. Fibrosis-dependent mechanisms of hepatocarcinogenesis. Hepatology. 2012; 56: 769-75.

14. Hirao H., Uchida Y., Kadono K. et al.. The protective function of galectin-9 in liver ischemia and reperfusion injury in mice. Liver Transplantation. 2015; 21(7): 969-81.

15. Rosen H.R., Biggins S.W., Niki T. et al... Association Between Plasma Level of Galectin-9 and Survival of Patients With Drug-induced Acute Liver Failure. Clinical Gastroenterology and Hepatology. 2016; 14(4): 606-12.

16. Matsuoka N., Kozuru H., Koga T. et al.. Galectin-9 in autoimmune hepatitis: Correlation between serum levels of galectin- 9 and M2BPGi in patients with autoimmune hepatitis. Medicine (Baltimore). 2019;98(35):e16924.

17. .Cacciato V., Casagrande E., Bodini G. et al.. Eradication of hepatitis C virus infection disclosing a previously hidden, underlying autoimmune hepatitis: Autoimmune hepatitis and HCV. Ann Hepatol. 2020;19(2):222-5.

18. Sanchez-Fueyo A., Tian J., Picarella D. et al. Tim-3 inhibits T helper type 1-mediated auto- and alloimmune responses and promotes immunological tolerance. Nat. Immunol. 2003; 4: 1093-1101.
19. Pacella I.,Timperi E., Accapezzato D. et al... IFN-a promotes rapid human treg contraction and late Th1-like treg decrease. J Leukocyte Biol . 2016;100(3):613-23. D0l: 10.1189/jlb.5A0415-140R.

20. Patent U.A. 43305 A, kl. G01N 33/92, publ. 10.08.2009. Link code <a href=shttp://uapatents.com/2-43305-sposib-diagnostiki-nayavnostigostrogo-zapalnogo-procesu.html» target=»_blank» rel=»follow» title=»

Sorce of fund: grant of the Scientific Society of Students and PhD-students of Sumy State University.

The work was performed within the framework of: research work of the Department of Infectious Diseases with Epidemiology of Sumy State University (SSU) "Common Infectious Diseases of the Northern Region of Ukraine: Modern Approaches to Diagnosis and Treatment" (state registration number 0117U003216) (deadline: 2017-2022).

\section{ORCID and contributionship:}

Mykola D. Chemych: 0000-0002-7085-5448 A, C, D, E, F

Anastasiia G. Lishnevska: 0000-0002-3388-1508 A, B, C, D, E, F

\section{Conflict of interest:}

The Authors declare no conflict of interest.

\section{CORRESPONDING AUTHOR Anastasiia G. Lishnevska \\ Sumy state university \\ 2 Rimsky-Korsakov St., 40000 Sumy, Ukraine \\ tel: +380997972740 \\ e-mail: a.lishnevska@kinf.sumdu.edu.ua}

Received: 18.12 .2020

Accepted:02.04.2021

A - Work concept and design, B - Data collection and analysis, C - Responsibility for statistical analysis, D-Writing the article, $\mathbf{E}$-Critical review, $\mathbf{F}$ - Final approval of the article 